had some further acquaintance with deductive geometry in the form of riders and later propositions, though in many cases the proofs have been learnt for purposes of reproduction.

Again, Prof. Carslaw objects to the use of the idea of direction in dealing with parallels and the angle-sum theorem-we should quite agree with him that such a treatment would not be satisfactory in a deductive course, but we differ most strongly from him in thinking that a deductive treatment of parallels, \&c., is necessary or wise in the first two years of geometry. The fact is, deductive geometry is not a suitable study for children before the age of twelve, and even at that age it must be a difficult study, and the deductive treatment of congruence and parallels is one of the most difficult parts of the subject, and should certainly not precede the deductive treatment of the parallelogram and the circle. We can only regret that New South Wales has been frightened by difficulties which were bound to arise in a period of transition, into going back to the old methods instead of boldly remedying the evil by helping all teachers to get the spirit of the new methods.

The report goes on to consider trigonometry and mechanics, but there is nothing that calls for serious comment.

R. Y. S.

\section{TSETSE-FLIES AND SLEEPING SICKNESS.}

A DEPUTATION representing eight missionary societies at work in Nyasaland waited upon the Secretary of State for the Colonies on November 23 in order to urge that game restrictions should be removed over a whole or part of the protectorate, on the ground that the tsetse-fly was suspected of spreading sleeping sickness, and that the destruction of big game "might" eliminate the fly. In his reply, Mr. Harcourt very wisely deprecated hasty action in a matter in which "the best-informed people were the least positive as to the facts."

It is by no means certain that the destruction of the larger mammalian fauna would have any such effect as the members of the deputation seem to anticipate. In the first place, it is highly probable that the primary host of the trypanosome of sleeping sickness is man, and that if the trypanosome is now to be found in wild mammals in regions in which the disease is known to have been introduced in recent times, it is because it has been transmitted to them from human beings by the agency of the tsetse-flies. Secondly, it is very far from certain that the destruction of the larger mammalia would have the effect of eliminating tsetse-flies, which can suck the blood of any kind of vertebrate animal, and which swarm in parts of the Uganda Protectorate (for example, on small uninhabited islands in the Victoria Nyanza) where there are no larger mammalia. Thirdly, the danger must be reckoned with that to deprive the tsetses of a large portion of their natural food-supply might have the effect of forcing them to supplement the deficiency elsewhere, and might therefore render them much more aggressive towards men and domestic animals, and in this way more efficient in spreading trypanosome diseases.

Everyone with a knowledge of the complicated problems involved in the subject of the transmission of trypanosomes by tsetses will deprecate ill-considered destruction of the big game, an action which, while robbing large tracts of country of one of their most beautiful and valuable features, may very well have the effect of upsetting the balance of nature in a manner that would greatly aggravate the evils which it is desired to combat.

NO. 2 I96, VOL. 88]
THE INTERNATIONAL CONFERENCE AT PARIS ON NAUTICAL ALMANACS.

$\mathrm{N}$ the initiative of the Bureau des Longitudes, the directors of the various national ephemerides were invited by $M$. Baillaud, director of the Paris Observatory, to assemble there on Monday, October 23. The objects of the reunion were to consider what steps, if any, should be taken to extend the scope of the various ephemerides for the purposes of astronomy, and at the same time to effect economy by combined action and interchange of computations. A small number of the leading practical astronomers were also invited to represent the needs of astronomy of precision.

The first general meeting was held at the Observatory at Io a.m., Monday, October 23. On the motion of Sir David Gill, M. Baillaud took the chair, having on his right $M$. Bayer, secrétaire de l'enseignement supérieure, representing M. Steeg, Ministre d'Instruction publique.

On the motion of M. Baillaud, Sir David Gill, as président d'honneur du Congrès de la Carte du Ciel, was nominated président d'honneur of the reunion, Dr. O. Backlund, imperial astronomer of Russia, vicepresident, and $\mathrm{Mr}$. $\mathrm{H}$. Andoyer, of the Bureau of the Connaissance des Temps, together with the Comte de la Baume Pluvinel, were nominated secretaries. There were present:-Prince Roland Bonaparte (member of the Academy of Sciences); Messrs. Cowell ("Nautical Almanac," London), Fritz Cohn (Berlin), Eichelberger (Washington), Général de Azcarate (San Fernando), Boccardi (Turin), as directors of ephemerides; Messrs. Dyson (astronomer royal, Greenwich), Hough (H.M. astronomer, Cape of Good Hope), Perrine (Cordoba), André (Lyons), Picart (Bordeaux), Verschaffel (d'Abbadia), as directors of observatories; and, as representatives of the Bureau des Longitudes MM. Bigourdan (president), Poincaré, Radau Deslandres, Hanusse.

The meeting was opened with an admirable address by $M$. Baillaud, and with a cordial speech of welcome by $M$. Bayer on behalf of the Minister of Public Instruction. After some discussion, resolutions, recommending the adoption as soon as possible of Greenwich mean time as the argument for all predictions in nautical and astronomical ephemerides, were unanimously passed. In the afternoon of the same day the members of the congress attended by invitation the meeting of the Academy of Sciences at the institute, and in the evening were entertained at a banquet in the Observatory, at which M. Steeg, Minister of Public Instruction, was present. The toast of "The President of the French Republic" was proposed by Sir David Gill, to which an interesting and eloquent speech was made, in reply, by $M$. Steeg. The health of M. Baillaud was proposed by Dr. Backlund.

Further meetings of the congress were held on October 24 and 25, and at the conclusion of the meeting on October 25 a unanimous agreement on all points was reached. On Thursday, October 26, the directors of the nautical almanacs met in committee to make final cooperative arrangements and report to the general congress; their report was unanimously adopted at an afternoon meeting on the same day.

A translation of the resolutions adopted is subjoined. It is impossible to overrate the good will and cordiality which pervaded the meeting, or the kindness and hospitality of our hosts. Besides the official banquet on Monday, private dinner-parties were given by M. Andoyer on the Tuesday, by M. Baillaud on the Thursday evening, the latter followed by a reception; a luncheon and reception were also given on the Friday afternoon by. Prince Roland Bonaparte, and 
boxes at the theatre and Opera were placed at the disposal of members of the congress.

The results of the congress promise to be of great interest and value, not merely by extending the scope and utility of the national ephemerides for the purposes of practical astronomy, but by the facilities which the universal adoption of Greenwich time offers for the comparison of the different lunar and planetary tables.

A probable sequence to these resolutions will be the universal adoption of Greenwich as the origin of longitudes in all future maps and hydrographic charts. The gain in simplicity and convenience will be immense.

Let us hope that England will respond to the international compliment thus paid to her by the adoption of the metric system of weights and measures.

\section{Resolutions and Recommendations adopted by the} Conference.

The conference strongly recommends that:-

(I) In all ephemerides the ecliptic coordinates of the sun should be given for Greenwich mean noon, and that the equatorial rectangular coordinates should be given for midday and midnight of Greenwich mean time.

(2) The ecliptic coordinates of the moon should be given at least for oh. and I2h. or Greenwich mean time.

(3) The ecliptic heliocentric and geocentric coordinates of the planets should be given for oh. or $12 \mathrm{~h}$. of Greenwich mean time.

(4) The ephemerides of the stars, that is to say, their correction from mean to apparent place, should be calculated for upper transit at the meridian of Greenwich.

The conference is of opinion that the adoption of the meridian of Greenwich for all ephemerides should be realised as soon as possible.

The conference is of opinion that in all catalogues and all collections of observations declinations instead of polar distances should be adopted.

The conference decides that those portions of the ephemerides which deal with the data necessary for the calculation of the perturbations of the small planets and comets shall be based on the masses of the planets adopted by Newcomb.

The conference decides that the names of stars shall be accompanied by a letter indicating their spectral type in terms of Pickering's notation. It is of opinion that these indications (so far as they have been determined) should in future be given in the list of 3064 stars to be published by the Bureau des Longitudes.

The conference decides that in future the stars in the fundamental and standard lists of Auwers, Boss, and Newcomb shall be designated by the letters $A, B, N$, and the Backlund-Hough stars by the letters $\mathrm{BH}$.

For the prediction of occultations of stars the list of the Nautical Almanac shall be adopted.

The commission adopts the following resolutions :-

For the sake of uniformity in the calculation of parallaxes, eclipses, and occultations, the ephemerides shall adopt for the value of the compression of the earth the number $1 / 297 \cdot 0$, resulting from the final researches of Messrs. Tittmann, Hayford, and Helmert.

For like reasons, in the calculation of eclipses, the semidiameter of the sun (Auwers) shall be retained, as already employed in all ephemerides.

The bureaux charged with the calculation of eclipses of the sun and moon and the occultations of stars shall choose in common agreement the tables and apparent diameters which they find most desirable, taking care to communicate in the most precise and complete fashion the data which they employ and the origin whence the adopted data have been derived.

The conference decides that the Connaissance des Temps shall continue to calculate the positions of the sun and of the planets from the Leverrier-Gaillot tables, but that bureau will in future compute the positions of the moon from the new tables of M. Radau, which are based upon Delaunay's theory. In the other ephemerides these calculations shall be based on the tables of Newcomb and of Hill No. 2 I96, VOL. 88 ] for the sun and planets, and on Hansen's tables, with Newcomb's corrections, for the moon until such time as the latter tables shall be replaced by the new tables of Brown.

This second series of solar, planetary, and lunar calculations shall be undertaken by the Nautical Almanac Office, with the exception of the ephemeris of Mercury, for which the office of the "Berliner Jahrbuch" shall be responsible.

\section{Relative to the Stars.}

(I) The corrections from mean to apparent place of the stars BH shall be computed at the National Almanac Office, and be printed by the Observatory of Pulkowa; the same will apply to the daily corrections of the principal fundamental clock-stars, which latter shall include the lunar terms of short period.

(2) The ephemerides of such of the stars A, B, N as do not occur in the list of Auwers stars, which is published annually in the "Berliner Jahrbuch," shall be calculated and printed in the observatory at Turin.

(3) The ephemerides of the Auwers stars shall be calculated and printed by the "Berliner Jahrbuch," with the exception of the 343 stars printed within brackets; the calculation of the ephemerides of these latter shall be undertaken by L'Almanaque Nautico.

(4) The ephemerides of the pole-stars, that is to say, of all the stars situated within Io degrees of north or south polar distance which are to be found in the provisional list of 3064 stars published by the Bureau des Longitudes, and of the other polar stars hitherto given in the ephemerides, shall be calculated from day to day by the Bureau des Longitudes, and shall contain the terms of short period, the values of which shall be separately indicated, however; for polar stars situated between $80^{\circ}$ and $83^{\circ}$ declination it will be sufficient to give the ephemerides for each alternate day.

The Connaissance des Temps undertakes to print all the ephenierides of the above-mentioned stars which are not given in other similar works.

The ordinary ephemerides of the stars shall be calculated to o.ooIs. in R.A. so far as $60^{\circ}$ of declination and $0.0 I^{\prime \prime}$ in declination, not for each tenth day, but for each tenth successive culmination at the meridian of Greenwich in order to facilitate interpolation; they will be accompanied with the data necessary for the computation of the terms of short period.

The calculation of the constants of reduction shail be carried out by each bureau in their usual way with four or five decimals.

\section{Relative to Eclipses and Occultations.}

The calculation of eclipses of the sun and moon shall be made (in conformity with the rules established by the preceding resolutions) once by the American ephemeris and once by the Connaissance des Temps.

The computation of occultations shall be made in duplicate by the American ephemeris.

The predictions of eclipses and the elements of occultations shall be calculated with all possible precision.

\section{Relative to Satellites.}

(1) The calculation of new ephemerides of the four principal satellites of Jupiter and their phenomena shall be made by the Bureau des Longitudes, and be based on Sampson's new tables.

(2) The ephemerides relative to the ring and to the satellites of Saturn (with the exception of Phœbe) shall be calculated by the "Berliner Jahrbuch."

(3) The calculations of the ephemerides of the satellites of Mars, of the new satellites of Jupiter, of Phœbe, and of the satellites of Uranus and Neptune shall be made by the American ephemeris.

The ephemerides relative to physical observations of the sun, moon, planets, \&c., shall be calculated by the American ephemeris, except the ephemeris of the crater Mösting A, which will continue to be published by the "Berliner Jahrbuch."

The computation and printing of the ephemerides of the small planets and variable stars shall be undertaken by the "Berliner Jahrbuch." 
It is desirable that the calculations made by any one of the bureaux should be communicated to other bureaux, which have to use them at least three years in advance.

The above conventions will be put in force in such a way as to be complete in 1917 .

It is understood that the above arrangements are provisional, subject to approval by the Governments concerned.

\section{THE SOLAR PHYSICS OBSERVATORY.}

$W^{E}$ take the following from Wednesday's Times (November 29):-

At the Congregation on Thursday, December 7 , the following Graces will be offered to the Senate:-“'That the recommendations contained in the report, dated November 13, I911, of the Council of the Senate on the proposed transference of the Solar Physics Observatory to Cambridge-namely, (I) that the University accept the charge of the Solar Physics Observatory, subject to the conditions laid down in the letter from the President of the Board of Education; (2) that steps be taken to obtain the powers requisite for the suspension of the election to the Plumian professorship of astronomy and experimental philosophy when it next becomes vacant, for a time sufficient to enable the University, if necessary, to obtain changes in the statutes which define the title of the professorship and the duties of the professor-be approved."

The proposal to transfer the Solar Physics Observatory to Cambridge was discussed in the Senate last Thursday. The proposal was warmly welcomed by Prof. Newall, Prof. Sir George Darwin, Prof. Sir Robert Ball, and Dr. Glaisher. The arrangements for organising the work of the department and for the provision of the necessary site were fully explained.

Nothing seems to have been said about the financial arrangements necessary to secure permanence. In the report of the so-called Departmental Committee the following passage occurs :-

With a view to securing the permanence of any arrangement that may now be made, the committee desire to point out the importance of attaching the directorship of the Solar Observatory, if established at Cambridge, to a professorship which is not merely of a temporary character. The University may not be in a position, at present, to give any definite assurance that the professorship will be renewed at the expiration of the present tenure; but we consider it highly desirable that the Government should ascertain, before coming to a final decision, whether the University is willing at an early opportunity to consider favourably the establishment of a professorship of astrophysics on a permanent foundation.

The "permanence" contemplated by the Council of the Senate only becomes operative on the death or resignation of the present Plumian professor. It is taken for granted that the unpaid professorship of astrophysics will not be vacated for any cause in the interval. What is to happen during a vacancy is not stated. Is this the kind of "permanence" contemplated by the Government? Is the next vacation of the Plumian professorship, which everybody hopes will not occur for many years, the "early opportunity" referred to in the report of the committee?

\section{NOTES.}

Following on the announcement last week of the appointment of an expert committee of investigation into the etiology, \&c., of foot-and-mouth disease comes the interesting and, if it should be confirmed, important announcement of the discovery of the causal organism of this serious animal scourge. This claim has been put forward by a German bacteriologist, Dr. Siegel, in a paper read at the annual Congress of Prussian Veterinary Surgeons in Berlin. Dr. Siegel claims to have found the No. 2 I96, VOL. 88] organism in the blood stream and in the local lesions in affected animals, to have cultivated it in artificial media, and that in experimenting with his organism it has satisfied the postulates of Koch. Moreover, he claims to be able to produce some degree of immunity to the disease. Details of this interesting paper are not yet to hand; and in the meantime the claim must be accepted with the reserve which must obviously be accorded to the statement of the discovery of an organism that has up to the present eluded vigorous and systematic research by other experts of almost all nationalities. In the meantime, the full details of experiments will be anxiously awaited; and if they warrant it, it will be one of the first duties of the British expert committee to investigate them carefully, and either to confirm or refute the claims of Dr. Siegel. Should the discovery be confirmed, it will indeed be an enormous boon to the whole agricultural world.

THE Bradshaw lecture is to be delivered at the Royal College of Surgeons on December 6 by Mr. R. Clement Lucas, who has chosen for his subject "Some Points in Heredity."

THE Paris correspondent of The Times reports that Prince Roland Bonaparte has placed at the disposal of the French Academy of Sciences a sum of 10,0ool., which is to serve as a fund in aid of those of its members who are engaged in research work.

THE superintendent of the Indian Museum informs us that Mr. J. Coggin Brown, curator of the museum of the Geological S drvey of India, accompanies the Abor expedition as geologist The botanical work is in the hands of Mr. I. H. Burkill, reporter on economic products to the Government of India, while Mr. Stanley Kemp, assistant superintendent in the Indian Museum, is in charge of both zoology and anthropology, with $\mathrm{Mr}$. R. Hodgart as taxidermist and assistant.

THE ringing of birds in order to study their movements has been referred to frequently in these columns. About twenty thousand birds have been ringed by correspondents of British Birds, the rings bearing the name of the editor of that journal, Mr. Witherby. One of these birds, a sea snipe, or redshank, was shot recently at Wesport, County Mayo, and it was assumed to be a bird escaped from captivity in London. A report in The Times of November 29 says :-_" The incident has caused much local interest, since nobody in Connaught has ever heard of a tame redshank. It has among seabirds the reputation of being remarkably shy." Local opinion in Connaught as to the difficulty of taming a redshank need not be disturbed. The bird referred to was probably ringed by one of Mr. Witherby's correspondents far away from London, and it is unlikely that it was ever in a cage.

Lieut.-Colonel Edgar A. Mearns, U.S.A., retired, associate zoologist of the United States National Museum, who accompanied the Smithsonian Expedition to Africa, under the direction of Colonel Theo. Roosevelt, will be attached as naturalist to the Childs Frick Abyssinian Expedition, which will sail from London shortly to make natural history collections in the Abyssinian region. It is proposed to make as complete a collection of the animals of the Abyssinian region as possible. The journey will be primarily through Abyssinia, but will extend into British East Africa as well, and cover a portion of that country north of the field gone over by Colonel Roosevelt in 1909-10. One of the most important regions to be visited is in the neighbourhood of Lake Rudolf, and along the shores of the lake itself. It is expected that the opera- 